\title{
Diversity Index Design of Ecological Water Resources Based on Computer Statistics
}

\author{
Hui Zhou, Lei Gong \\ College of Civil Engineering and Architecture, Guizhou University, Guiyang, China \\ zh_ou_hui@126.com
}

Keywords:spatial pattern;diversity index formula; plaque type; landscape element; mathematical statistics

\begin{abstract}
Through the research and summary on ecological water resources in the production, living and ecological tourism and other aspects in Xiangzhigou of Wudang District Xinbao village,according to the climate characteristics and regional pattern of Guiyang xiangzhigou, this paper set the simple quantitative index structure, space configuration and other aspects of ecological water resources, the spatial pattern of ecological water resources index system of water resources and ecological landscape diversity index. Through investigation and analysis, concluded the landscape ecological water resources quality indexes in recent years. Finally, put forward the positive suggestion of ensuring the ecological environment and water after the tourism volume increased.
\end{abstract}

\section{Introduction}

Xiangzhigou is located in 35 kilometers northeast of Wudang District Xinbao village in Guiyang, this is a simple and natural copycat, is a quiet beautiful world. Its 45 kilometers far away from the Guiyang[1]. The gross area of scenic area is 50.8 square kilometers. This area distribue mountain, water, stone, forest, cave, waterfall, canyon, karst landscape, ancient culture, ethnic customs, each have unique feature and high value[2]. In addition, Xiangzhigou is the ancient relic of ancient Cai Lun paper-making. The old, integrited original handmade paper mill, simple and elegant minority wood structure residence well-proportioned decoration to the landscape.

\section{The application of water resources in the production}

Historically, the residents of Xinbao village Xiangzhigou subsisted mainly on agriculture, supplemented by old papermaking in spare time to make a living. In Xiangzhigou, the main water source is the Baishuihe passes through the village, Baishuihe along the main road of xiangzhigou from top to bottom, pass through the whole Xiangzhigou, for the surrounding farmland irrigation, livestock, poultry farmers' drinking, as well as the fishery breeding. In the downstream of the ditch, after lot of stream of water gathered, the water potential is bigger than upstream, so the residents built a lot of paper mill along the river[3,4]. These workshops are built by ancient ancestors after a generation to generation of inheritance, continue to use up to now. The workshop rely on water flow to drive the rotation of the rotating wheel, thereby maintaining the normal work of the whole worksho. The workshop make full use of the local terrain, the terrain, as well as local ecological water resource. In the downstream of Baishuihe, originally built 4 paper mills, now in order to reduce sewage produced by the pollution industrial paper. Due to the government's construction tends to more rational, humane and sustainable, local government has gradually closed 4 original paper mills in downstream, and rejected all foreign businessman who want to do investment and construction.

On the whole, the residents of Xiangzhigou on local ecological water resources in the production show reasonable level sense, the overall sense and three-dimensional sense, fully utilized the local ecological water resources in the production. 


\section{The application of ecological water resources}

A. The application of ecological water resources in life

According to the visit investigation, at present all residents use is the villagers through financing and government grant money from the collective mountain down the mountain spring water. Mountain spring water trickle flow not to cease, supply the whole Xiangzhigou residents living water uninterrupted, so that the residents were able to maintain normal daily life. According to respondents said, the local drinking water has been relatively sTable, the situation of lack of drinking water is less. The springs supply water can not only meet the residents' daily drinking, as well as the poultry drinking, but also have enough water for daily washing. So we can see that, the water resources of Xiangzhigou is very to ensure the residents' daily life.

TABLE I. THE ECOLOGICAL WATER RESOURCE QUESTIONNAIRE OF GUIYANG XIANGZHIGOU SCENIC SPOT

\begin{tabular}{|c|c|c|c|c|c|}
\hline \multicolumn{5}{|c|}{ Scenic area water resources } & \multirow[b]{2}{*}{$\begin{array}{l}\text { Ecological water } \\
\text { environment area }(\mathrm{m} 3)\end{array}$} \\
\hline $\begin{array}{l}\text { Moisture } \\
\text { content (m3) }\end{array}$ & $\begin{array}{l}\text { Surface water rich } \\
\text { area }(\mathrm{m} 3)\end{array}$ & $\begin{array}{l}\text { Living water } \\
\text { (m3) }\end{array}$ & $\begin{array}{l}\text { Industrial land use } \\
\text { water }(\mathrm{m} 3)\end{array}$ & Subtotal & \\
\hline 41826.06 & 6324.03 & 7386.95 & 7633.5 & 63170.54 & 9886 \\
\hline
\end{tabular}

B. The application of ecological water resources in ecological tourism

The tourism industry of Wudang district started in August 1994, received strong support from the provincial, city, district governments at all levels and the relevant departments. In 1995, initiated the development of Guiyang xiangzhigou scenic area. During the six years till 2000, the total investment amounts for area developent is about 5000000 yuan. In recent years, Xiangzhigou focus on the development of tourism, to promote local economic development, increase the dweller's income, improve dweller's life, relying on abundant natural landscape resource of Xiangzhigou, developed the Guodijing, Nanjing temple, Longjing Bay, MaJiaochong 7 scenic spots, and built Xiangzhigou provincial tourism scenic area[5].

The river in Scenic area belong to Wujiang water system, a tributary of Nanming River, which is made up by Adu river, Baishuihe, Longquan River three tributaries. The precipitation in this area is very rich, with an average annual rainfall of about $1200 \mathrm{~mm}$, and the exposed strata with low water permeability, has developed surface water system, the average drainage density is $13 \mathrm{~km} / \mathrm{k} \mathrm{m}^{2}$. The groundwater and surface water changes very frequently, many spring water exposed, almost all rivers and tributaries from the origin of underground river or Karst springs. No matter surface water or groundwater, water calcium, magnesium ion content are high, generally up to $250 \sim 300 \mathrm{mg} / \mathrm{L}$, $\mathrm{pH}>7.5$. More than 60 various types of spring. According to the research by geological experts, the Wudang geothermal resources are very rich, the current proven development Xiangzhigou spa, water yield of up to 800 tons to 1000 tons, the water temperature reaches 45 to 65 degrees, wellhead temperature up to $47^{\circ} \mathrm{C}$, up to 70 degrees. Using this feature, the tourism resources of Xiangzhigou are fully developed, built Xiangzhigou Lake Hot Springs Resort, serve the hot springs as the center industry, leisure, catering, entertainment, health and other outspread industry, drove Xiangzhigou tourism development and the economic development.

ADu river area has 3 level one scenery, 6 level two scenery; 5 grade three scenery, a total of 15 features, distributed in 4 village within 7 village in Xinbao village. On the whole, the area ia very large, the village, population is much, development degree is big. Landscape resources ratio is low, the environment quality is poorer, partial place need to restore the ecological environment, such as the north of Xinbao village. But the economy of this state is good, traffic is convenient.

Longquan river area has natural forests as level one scenery, 2 level two sceneries ; 2 grade three sceneries, a total of 5 sceneries. Resources can be, environmental quality is better, for the northern part is high mountain climate, which is better for summer. Longjing has big water yield and good water quality, is of great value to be developed, the traffic is convenient, is convenient for the 
development, it has great promise in the development of summer leisure tourism and ethnic tourism .

BaiShuihe area has 4 level one scenery, 14 level two scenery; 24 grade three scenery, a total of 49 scenery. Distributed in the largest village Longjiao village among the 7 Villages of Xinbao village. The scenic resources are mainly concentrated in this village, and mainly concentrated in the northern village.

\section{The ecological water resources planning and design of Xiangzhigou scenic spot in Guiyang}

According to climate characteristics and regional pattern of Guiyang Xiangzhigou, we set the simple quantitative index on ecological water resources' structure, space configuration and other aspects. As shown in Figure 1.

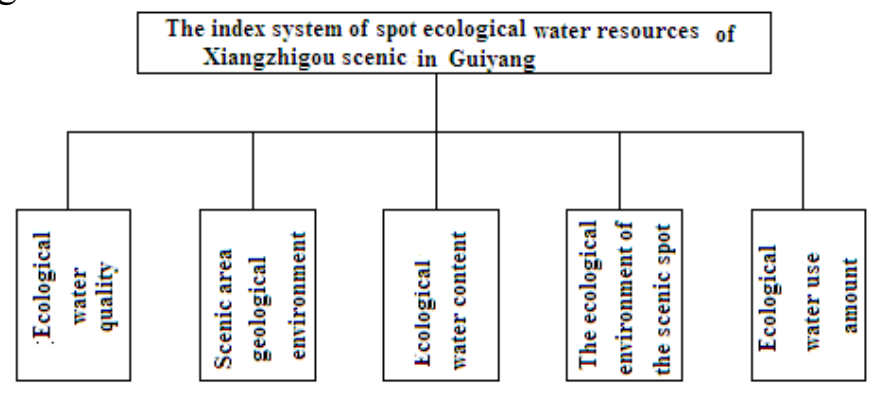

Figure 1. The index system diagram of ecological water resources spatial pattern

Combined with Guiyang Xiangzhigou climate data to establish Guiyang Xiangzhigou scenic water ecological space pattern index system including ecological water distribution spatial characteristics, geological environment characteristic and ecological scenic water content spatial relationship. These factors are quantified using angles to reflect Guiyang Xiangzhigou landscape ecological water condition, also as an important measure of ecological water resources quality.

Landscape ecological water resource diversity index is determined by the number of elements of landscape ecological water resources and each factor accounted for a change to reflect. If the elements of a landscape, ecological water resource diversity index is zero; and when the element is greater than two, the element type accounted for equality, the landscape ecological water resource diversity is highest; when each element type ratio difference is increased, so the landscape water ecological diversity will drop. Diversity index formula is as follows: S, I, m, ri respectively refers to denote ecological landscape diversity index, landscape water ecological water area ratio, the number of types of elements, ecological water resource element type[6].

$$
S=\sum_{i=1}^{m} r_{i} \times y n r_{i}
$$

Landscape water ecological dominance index, refers to some landscape ecological water resources feature types accounted for the main control extent, namely ecological water resource diversity compared with the greatest diversity of deviation extent. If the advantage degree is large, then the corresponding to the degree of deviation is also greater, that ecological water element type comparative advantages; if the dominance index is smaller, the degree of deviation is small, the landscape in ecological water resource element type accounted for no obvious difference; if the advantage degree is zero, i.e. Various types of accounts than the equal, there is no relative advantage. The dominance index, $\mathrm{n}$ refers to landscape types of plaque volume; plaque ij area ( $\mathrm{m} 2)$ are denoted by aij; B refers to landscape ecological water area $(\mathrm{m} 2)[7]$.

$$
r_{i}=\sum_{i=1}^{m} a_{i j} / B \times 100 \%
$$

Ecological water resource plaque types is influenced by the humanities environment and nature, from large to small, from quantitative change to qualitative change process, which is from simple to difficult change, that is the extent of the damage to the landscape water resources in human activities, more feedback behavior for the landscape ecological planning of water resources effect degree, it is in the range of 0 to 1 , when there is no fragmentation is zero, when destroyed is 1 . Landscape damage index $\mathrm{D}, \Sigma \mathrm{Mi}$ is all landscape types of plaque[8].

$$
D=\sum M_{i} / B
$$


Landscape ecological water resources element types in reality space distance is adjacent, can be expressed as the plaque adjacent index. Class $\mathrm{i}$ and class $\mathrm{j}$ plaque plaque intersection length distance kij, said $\mathrm{Nj}$ refers to ecological water resource plaque edge total length of class j[9].

$$
F k=k_{1 j} / N_{j}
$$

Conducted investigation the ecological environment of water resources in Guiyang Xiangzhigou scenic area, survey data is shown in Table 1.

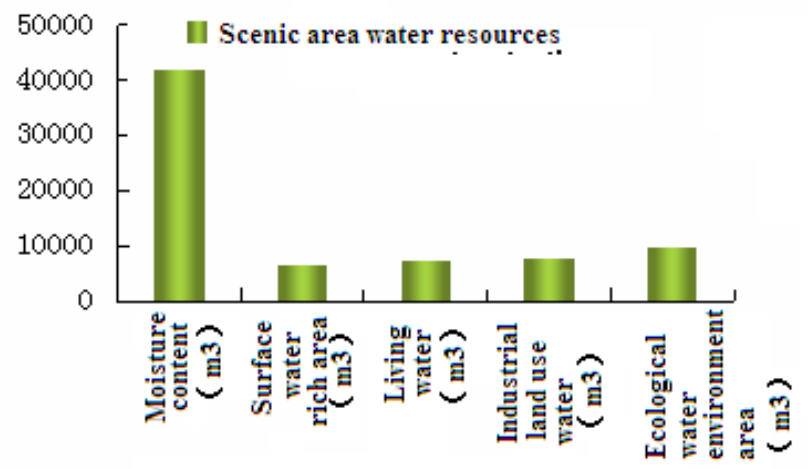

Figure 2. The ecological water use distribution map of Guiyang Xiangzhigou scenic spot

Selected the landscape ecological water resources spatial pattern factors in the index system, and investigate quality index changes in the year 2010 2009, 2011 three years in various types of landscape ecological water resources, survey results are shown in Figure 3

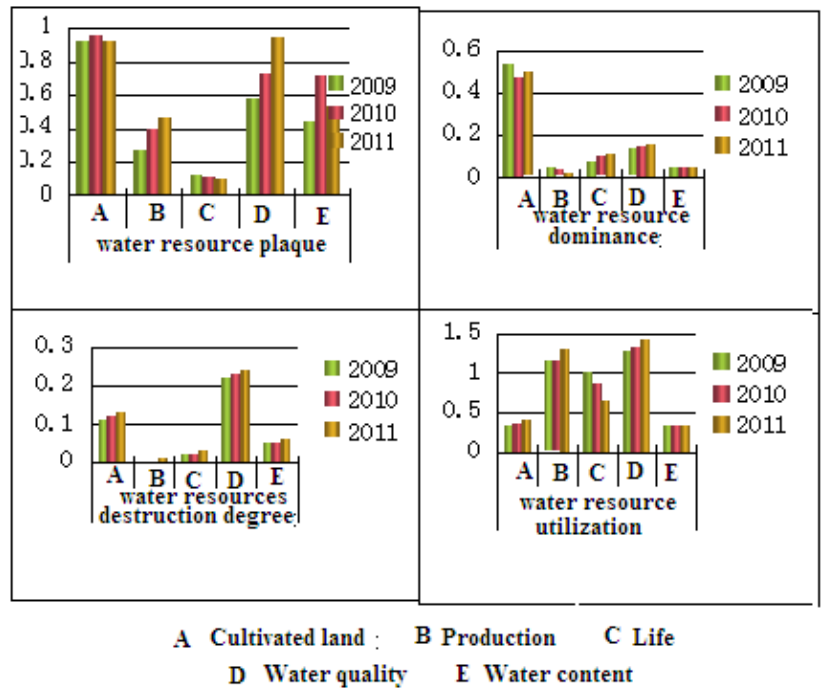

Figure 3. The index annual comparison chart of all types of landscape ecological water resources quality

As chart shows, the spatial pattern factors of the various elements of water resource in Guiyang Xiangzhigou scenic spot ecological all in a state of comparative advantage. It is stated that the regional ecological water resource in this area in recent years plays an important role in the planning process of scenic spot.

\section{Conclusion}

At present, Xinbao village is in the early stages of development, economy is owed develop, tourism resources also has just started, so the pollution by local ecological environment water and living water is not serious. But with the rural tourism resources development and indigenous paper production in Xinbao village, the water resources is polluted in a certain way.

In order to develop tourism resources, benefit to people,Xinbao village government planning to constructe tourism resort and spa in Xiangzhigou scenic area, with the increased amount of tourism, this will have certain effect on the ecological environment and water to production. According to this, we put forward the following suggestions: 
(1) To control sewage of Longshang village's paper mill . Move forward, built the paper mill together, common to sewage treatment in emissions, in order to avoid pollution of water ecological environment.

(2)Establish life sewage and garbage collection processing system, papermaking factory built together,set sanitation supervision and management the sell team, at any time processing of dirty, disorder and poor problem.

(3) Set protection zone delineation of scenic river, creek water, mainly protected the plant landscape. Control the emission standards of the existing outfall inspection, cleaning.

(4) Set restrictions on the use of pesticides and fertilizers on both sides of the river ridge within the farmland, advocate scientific farm, improve cultivation technology.

(5) Advocated the little influence on the environment of " eco tourism ", develop ecological traffic,do not set roadway in where can walk.

(6) In order to coordinate landscape ecology and tourism environment, the scenic farmland, vegeTable field pastoral scenery as ecological sightseeing agriculture garden, to the village, farm as a new tourism elements.

(7) Strengthen the village green, change the energy structure, build firedamp pool, energy saving stove or the use of electric heating, strengthen the solid waste removal management.

\section{Acknowledgments}

This paper belongs to achievements of the project supported by Guizhou University with the name The sustainable development of water resources in tourism area based on the ecological footprint model - Taking Xinbao village of Wudang District in Guiyang as an example and the Project number X102028.

\section{References}

[1] Feng Shangyou. Water resource sustainable utilization and management of [M]. Beijing: Science Press, 2012:56-57.

[2] Guo Shenglian. Water problem research and progress of [M]. Wuhan: Hubei science and Technology Press, 2008:57-59.

[3] Liu Changming, Chen Zhikai. Chinese water problem of twenty-first Century [M]. Beijing: Science Press. 2011:235-237.

[4] Ren Shumei, Yang Peiling . Water resources protection [M]. Beijing: China Water Power Press, .2010:178-179.

[5] Zhang Tingwei, Feng Hui, Peng Zhiquan. City waterfront design and development [M]. Shanghai: Tongji University press, 2012:6-25

[6] Beijing water resources planning and Design Institute. When the memory is open to the river: poster design[M] . Beijing: China Water Power Press, 2009:8-27

[7] $\mathrm{Wu}$ Wenying city waterfront landscape ecological pattern [J]. Journal of Minjiang University, 2011(4):100-103

[8] Ma Huiling. City waterfront landscape design theory[D]. Master Dissertation of Beijing Forestry University, 2012.

[9] Li Linxue. City waterfront space morphology of the integration era building[J].Journal of Southwest Forestry University, 2009 ( 3): 56-59 